BRIEF REPORTS

\title{
OSSIFICATION OF THE NORMAL FEMORAL CAPITAL EPIPHYSIS
}

\author{
R. J. STEWART, C. C. PATtERSON, R. A. B. MOLlAN
}

The apparent slope of a dysplastic acetabulum is greatly influenced by the position in which the radiograph is taken, and the diagnosis of congenital dislocation of the hip is sometimes unclear until the capital epiphysis becomes visible (see references). Our study aimed to identify the optimal time for radiographic demonstration of its presence.

We reviewed radiographs of the normal hips of 277 children aged under 12 months, being all those available from patients attending the Royal Belfast Hospital for Sick Children in 1979 and 1980, excluding cases of congenital abnormality, failure to thrive and congenital dislocation of the hip. Of these $58 \%$ were boys.

Results. No difference in ossification was found between left and right sides, so analysis was based on one hipthe left. The number and proportion of left capital epiphyses seen to have ossified by the end of each 30-day month after birth was recorded. These results were plotted as the percentage of epiphyses which had ossified against age and as percentage predicted from a probit model (see figure). This graph gives a prediction, month by month, of the percentage of hips which will be ossified, and shows that $90 \%$ of epiphyses will be visible on radiographs taken 200 days after birth. Ossification was slightly earlier in girls, though after six months there was little difference between the sexes.

Discussion. When there is radiological dependence on the presence of the femoral capital epiphysis in making a

R. J. Stewart, FRCS. Registrar in Surgery

C. C. Patterson. MSc, Lecturer in Medical Statistics

R. A. B. Mollan. MD. FRCS, Professor of Orthopaedic Surgery

Musgrave Park Hospital. Stockman`s Lane. Belfast BT9 7JB. Northern Ireland.

Correspondence to Professor Mollan.

( 1986 British Editorial Society of Bone and Joint Surgery $0301620 \times 864 \mathrm{R} 01 \$ 2.00$

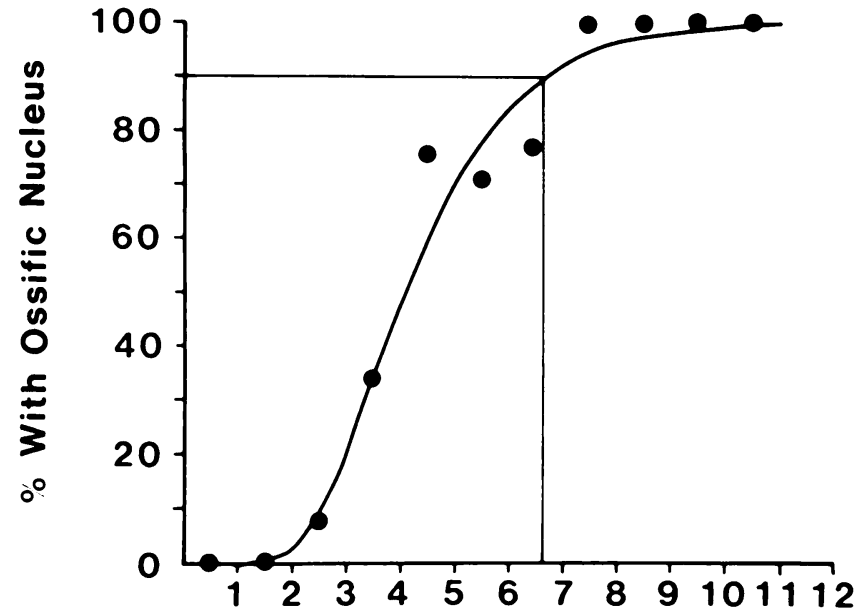

Age (Months)

Graph showing the percentage of ossified femoral capital epiphyses against the logarithmic age in 30-day months. The points show the actual results in 277 children. The line is a prediction derived from these results, which forecasts $90 \%$ ossification at 200 days after birth.

diagnosis of congenital dislocation of the hip. we suggest that further radiography be postponed to about six months after birth when there is a $90 \%$ probability that the femoral capital epiphyses will appear on the film. Maximum benefit can thus be gained from a single exposure.

\section{REFERENCES}

Andrén L, von Rosen S. The diagnosis of dislocation of the hip in newborns and the primary results of immediate treatment. Acta Radiol (Stockh) 1958:49:89 95.

Bertol P, Macnicol MF, Mitchell GP. Radiographic features of neonatal congenital dislocation of the hip. J Bone Joint Surg $[B r]$ 1982:64-B:176-9.

Krepler P, Mazoch R, Schwägerl W, Schuster E. Diagnosis and relevance of suspected dysplasia of the hip joint, radiologic investigation starting with the age of 3 months. Arch Orthop Trauma Surg 1982:101:29-37.

\section{SLIPPED CAPITAL FEMORAL EPIPHYSES IN IDENTICAL TWINS}

\author{
H. A. R. GAJRAJ
}

The exact aetiology of slipped femoral epiphysis is unknown. It is, however, known that sometimes it is familial. Gorin (1977) reported the occurrence of slipped epiphyses in both of one pair of identical twins and another pair is recorded in this paper.

Case report. An 11-year-old girl presented with pain in her left hip and left knee of 12 months'duration, limping with the leg laterally rotated. Abduction and medial rotation at the hip were limited. Her knee was clinically normal. Radiographs confirmed an advanced slip of the capital epiphysis of the left femur (Fig. 1) and a corrective subtrochanteric osteotomy was performed. 